\title{
Clinical features of infectious keratitis at a tertiary referral center in a rural area of Korea
}

\author{
This article was published in the following Dove Press journal: \\ International Medical Case Reports Journal \\ 7 December 2015 \\ Number of times this article has been viewed
}

\section{Seung-Jun Lee ${ }^{1, *}$ \\ Jang Hun Lee ${ }^{1, *}$ \\ Moosang Kim' \\ Sang Beom Han' \\ Joon Young Hyon ${ }^{2}$}

'Department of Ophthalmology, Kangwon National University Hospital, Kangwon National University Graduate School of Medicine, Chuncheon, ${ }^{2}$ Department of Ophthalmology, Seoul National University Bundang Hospital, Seoul National University College of Medicine, Seongnam, Korea

*These authors contributed equally to this work.
Correspondence: Sang Beom Han Department of Ophthalmology, Kangwon National University Hospital, I56 Baengnyeong-ro, Chuncheon, Kangwon 200-722, Korea

Tel +82332589210

$\mathrm{Fax}+82332582296$

Email m.sangbeom.han@gmail.com
Purpose: To evaluate clinical features of infectious keratitis at a tertiary referral center in a rural area of Korea.

Patients and Methods: This was a retrospective study. Medical records of 70 patients who were diagnosed with infectious keratitis and underwent corneal culture were reviewed. Data including demographics, predisposing factors, and microbiological profiles were collected and analyzed. Results: Age distribution showed one peak at sixth and seventh decade, and 48 patients $(68.6 \%)$ were $\geq 50$ years old. The male to female ratio was 43 (61.4\%):27 (38.6\%). Ocular surface disease was the most frequently found (48 cases, 68.6\%). Gram-positive bacteria were most common (ten patients, 66.7\%), followed by Gram-negative bacteria (three patients, 20\%) and fungi (two patients, $13.3 \%$ ). In this study, $34.3 \%$ of patients were treated by at least one topical antimicrobial before culture. Patients who received topical therapy before culture showed positive culture rate of $16.7 \%$, and patients who underwent corneal culture without topical antibiotics showed positive culture rate of $23.9 \%$. However, there was no statistically significant difference between the two groups in positive culture rate $(P=0.554)$.

Conclusion: The proportions of the elderly and male patients were higher than the young and female patients, respectively. Gram-positive bacteria were the most common pathogens, and ocular surface disease was the most common predisposing factor.

Keywords: infectious keratitis, corneal ulcer, Gram-positive bacteria, rural area

\section{Introduction}

Infectious keratitis is potentially devastating disease that can lead to serious visual impairment. ${ }^{1,2}$ To prevent permanent vision loss, early identification of causative organisms and prompt initiation of adequate antibiotics are important. ${ }^{3,4}$ Understanding the recent characteristics of infectious keratitis including predisposing factor and microbiologic profile are essential in the treatment of the condition. Clinical features of the disease vary according to age, area of inhabitation, socioeconomic status and general condition, and may also change over time.$^{5-7}$ Recently, for instance, infectious keratitis associated with contact lens (CL) wear in younger patients has increased with the corresponding widespread use of CL. ${ }^{5-7}$

Profiles of infectious keratitis have been reported worldwide, including those from Korea. ${ }^{1,3,5,6,8-12}$ However, to the best of our knowledge, information regarding infectious keratitis of patients residing in rural Korea has never been reported.

In this study, we investigated the clinical features of infectious keratitis including predisposing factors and microbiological profile at a tertiary referral center in rural area of Korea. 


\section{Patients and methods}

This retrospective study included 70 patients who were diagnosed with infectious keratitis and underwent corneal culture at Kangwon National University Hospital from June 2007 to October 2014. Medical records were reviewed and analyzed for data including demographics, microbiologic profile, and predisposing factors. The study conformed to the tenets of the Declaration of Helsinki. Ethical approval and patient consent was not obtained because this is a retrospective study in which only review of medical records was done.

In every case, scraping on the corneal lesion with a sterile blade was performed, and culture of the corneal sample was done using blood agar plate, chocolate agar plate, Thioglycollate broth, Sabouraud's agar, and Brain-Heart infusion broth. If there was growth on the cultures, Gram staining and potassium hydroxide mount were performed. Empirical medical therapy was started immediately after the corneal scraping. Most patients received combination of topical 10\% cefazolin and $2 \%$ gentamicin as a primary antibiotics treatment, and topical levofloxacin or moxifloxacin was used in some cases. In cases with corneal ulcer greater than $3 \mathrm{~mm}$ in diameter or rapidly progressing inflammation, $3.1 \%$ vancomycin and $2 \%$ amikacin were chosen as a primary treatment. Antifungal agents including $0.5 \%-3 \%$ amphotericin or $1 \%$ voriconazole were also initiated in cases with suspicious fungal infection. After culture results were available, we changed antibiotics based on the sensitivity tests.
Positive culture rates according to previous use of antibiotics were compared using Fisher's exact test, and $P$-value $<0.05$ was considered significant. SPSS for Windows (version 18.0, SPSS Inc., Chicago, IL, USA) was used for statistical analyses.

\section{Results}

Study population comprised $53(76 \%)$ men and 17 (24\%) women. The mean age of all subjects was $56.7 \pm 17.0$ years (range, $6-88$ years). Forty-eight patients $(69 \%)$ were $\geq 50$ years old, whereas eight patients $(11 \%)$ were $<40$ years old. Unimodal age distribution with a peak at fifth and sixth decades was observed. Details of age and sex distribution are shown in Figure 1.

Regarding predisposing factors, ocular surface disease was most frequently found (48 cases, $69 \%$ ). Corneal erosion was the most common disease (36 patients), followed by recurrent corneal erosion ( 3 patients), herpes keratitis (3 patients), bullous keratopathy (2 patients), graft-versushost disease ( 2 patients), neurotrophic ulcer (1 patient), and chemical burn (1 patient). Five patients (7\%) had a history of previous ocular surgery. Two of those patients had history of cataract surgery, and one patient had history of patch graft surgery due to scleromalacia perforans. One patient had received glaucoma filtration surgery and the remaining one patient had a history of pars plana vitrectomy. Corneal trauma was noted in 15 cases (21\%). Four of them had trauma with

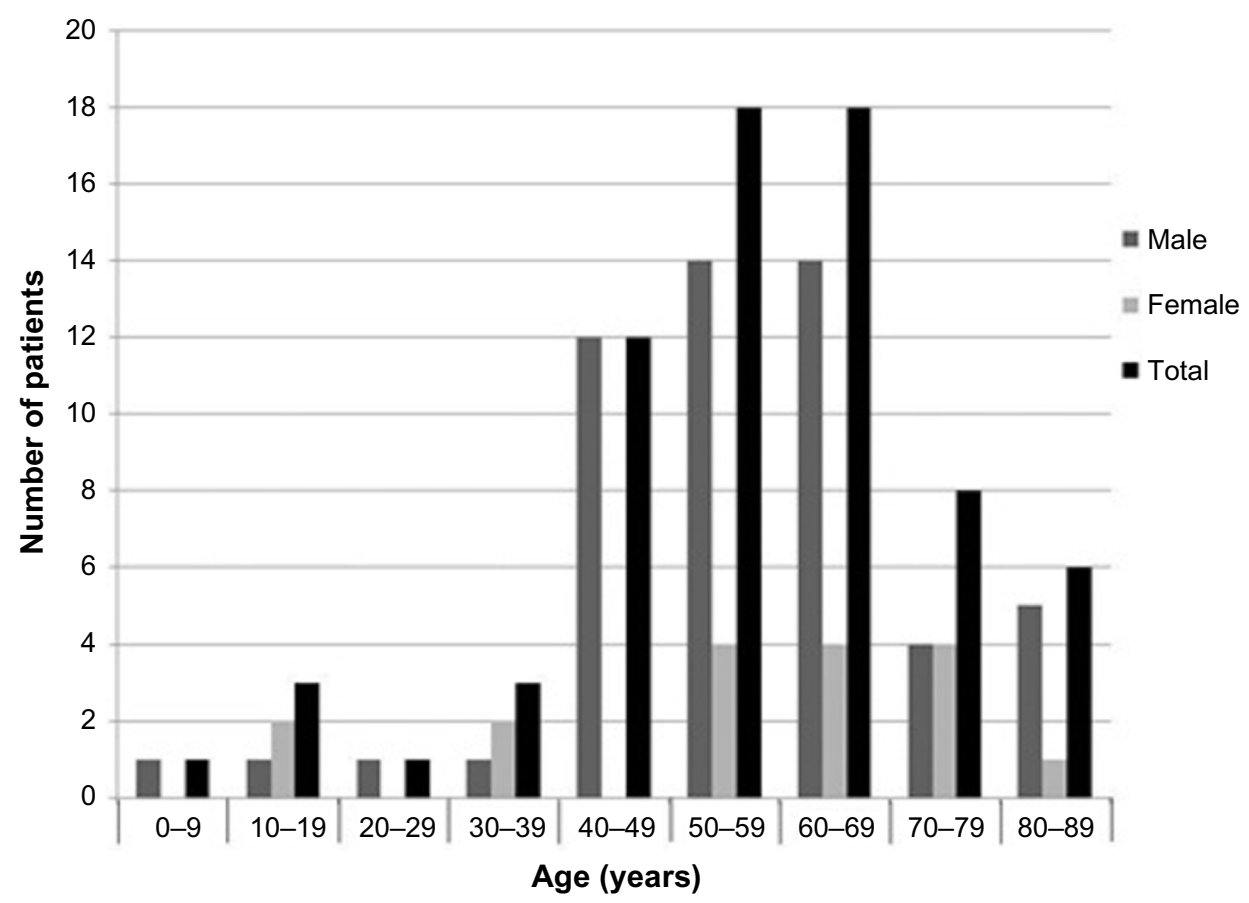

Figure I Distribution of the patients according to the age and sex. 
organic material and five patients had metallic foreign body in cornea. Fourteen of 15 patients with a history of corneal trauma were male patients. CL wear was reported in two cases $(3 \%)$. Predisposing factors of infectious keratitis are summarized in Table 1.

In 15 patients $(21 \%)$, corneal culture revealed positive results. Twenty-four patients (34\%) received treatment with topical antibiotics before referral. Positive culture rate was $17 \%$ (4 of 24 cases) in patients with prior treatment with antibiotics, and $24 \%$ (11 of 46 cases) in those who did not receive antibiotics treatment. However, no statistically significant difference was found in culture positive rate between the two groups ( $P=0.554$, Fisher's exact test). Table 2 shows comparisons of positive culture rates according to previous use of antibiotics.

Single microorganism was isolated in 14 patients, and two organisms were identified in one patient. Gram-positive bacteria was most common (ten patients, 67\%), followed by Gram-negative bacteria (three patients, 20\%) and fungi (two patients, 13\%). Culture results are summarized in Table 3.

\section{Discussion}

In the present study, we evaluated clinical features of infectious keratitis including age and sex distribution, predisposition factors, and microbiologic profile.

The age distribution showed single peak in patients aged in their 50 s and 60 s, and only $11 \%$ of patients aged $<40$. The results are inconsistent with the recent studies that demonstrated bimodal age distribution in the young and in the elderly. ${ }^{5-7}$ CL-related infectious keratitis was only two cases $(3 \%)$ in this study, which is in discordance with those of the previous studies in Korea that $26 \%-40 \%$ of infectious keratitis was associated with CL wear. ${ }^{13,14}$ Studies conducted in other countries also demonstrated that $30 \%-50 \%$ cases of infectious keratitis were associated with $\mathrm{CL}$ wear, and the incidence is higher in patients aged in their 20 s and 30 s. ${ }^{7,15}$ These results could be explained by the fact that Kangwon province is a rural area where proportion of elderly population is higher and only small population of youngsters reside.

Table I Predisposing factors for infectious keratitis

\begin{tabular}{ll}
\hline Factors & Number (\%) \\
\hline Total & $70(100)$ \\
Ocular surface disease & $48(69)$ \\
Corneal trauma & $15(21)$ \\
Corneal surgery & $5(7)$ \\
Contact lens & $2(3)$ \\
\hline
\end{tabular}

Table 2 Comparison of positive culture rates according to previous use of antibiotics

\begin{tabular}{|c|c|c|c|c|}
\hline & $\begin{array}{l}\text { Total } \\
(\%)\end{array}$ & $\begin{array}{l}\text { Antibiotics } \\
\text { (\%) }\end{array}$ & $\begin{array}{l}\text { No antibiotics } \\
\text { (\%) }\end{array}$ & $P$ \\
\hline No of cultures & $70(100)$ & $24(34)$ & $46(64)$ & \\
\hline Positive cultures & $15(2 \mid)$ & $4 / 24(17)$ & $11 / 46(24)$ & $0.554 *$ \\
\hline Polymicrobial & 1 & & 1 & \\
\hline Bacterial isolates & 13 & 3 & 10 & \\
\hline Gram-positive & 10 & 3 & 7 & \\
\hline Gram-negative & 3 & & 3 & \\
\hline Fungi isolates & 2 & I & I & \\
\hline
\end{tabular}

Note: $* P$-value was calculated by Fisher's exact test.

Abbreviation: No, number.

In the present study, the proportion of male patients was higher than female patients, which is in agreement with the male preponderance in the elderly reported in another study. ${ }^{16}$ It is conceivably due to the fact that males are more susceptible to trauma. In this study, 14 of 15 patients with infectious keratitis associated with corneal trauma were male.

The results that ocular surface disease was most common predisposing factor for infectious keratitis correspond well with the previous reports. ${ }^{5,7,16,17}$ Corneal trauma was the second common predisposing factor. Infectious keratitis after corneal trauma is common in undeveloped countries or rural areas, ${ }^{7,18,19}$ and decreased with economic development and urbanization. ${ }^{15,19}$ The relatively high proportion of corneal trauma might be explained by the fact that most of the patients included in this study were the elderly residing in rural areas and live on farming, thus having an increased risk of corneal trauma and exposure to pathogens.

Positive culture rate was $21 \%$, which is lower compared to the results of previous studies that causative microorganism was identified in $40 \%-68 \%$ of cases. ${ }^{1,5-7,9,20,21}$ Empirical

Table 3 Causative organisms isolated in cultures of corneal scrapes

\begin{tabular}{ll}
\hline Organism & Number \\
\hline Total & 15 \\
Gram-positive bacteria & 10 \\
Staphylococcus aureus & 3 \\
Staphylococcus capitis & 3 \\
Staphylococcus warneri & $\mathrm{I}$ \\
Staphylococcus hominis & $\mathrm{I}$ \\
Micrococcus species & 2 \\
Gram-negative bacteria & 3 \\
Escherichia coli & $\mathrm{I}$ \\
Serratia marcescens & $\mathrm{I}$ \\
Hafnia alvei & $\mathrm{I}$ \\
Fungus & 2 \\
Fusarium & $\mathrm{I}$ \\
Alternaria & $\mathrm{I}$ \\
\hline
\end{tabular}


antibiotics treatment, slow growth of microorganisms on culture media, other causes of keratitis including virus and improper corneal sampling might account for the low positive culture rate in this study. ${ }^{8}$ Patients with prior topical therapy had lower positive culture rate compared to those who did not receive antibiotics treatment before referral, although the difference was not statistically significant. Prior studies demonstrated that empirical use of antibiotics is associated with decreased positive culture rate., ${ }^{1,6}$ Meanwhile, van der Meulen et $\mathrm{al}^{6}$ showed the rate that culture outcomes affected modification of initial antibiotic therapy was only $4.5 \%$, suggesting the effectiveness of empirical treatment with antibiotics. With the development of antibiotics, such as fourth-generation quinolone including moxifloxacin and gatifloxacin, the effectiveness of empirical treatment with commercially available antibiotics can be enhanced. For instance, Sharma et $\mathrm{al}^{22}$ recently revealed that $0.5 \%$ moxifloxacin monotherapy is equally effective as combination therapy using fortified cefazolin and tobramycin in the treatment of moderate bacterial corneal ulcers.

In this study, Gram-positive bacteria were the most frequently identified pathogen, and Staphylococcus species was the most common Gram-positive bacteria, which is in agreement with previous reports. ${ }^{1,7,20,23}$ By contrast, several recent studies demonstrated high incidence of keratitis caused by Gramnegative bacteria, especially Pseudomonas aeruginosa., 5,6,21,24 Prior studies in Korea also reported that Pseudomonas species was the most common pathogen. ${ }^{13,14}$ The results of the present study are in discordance with those studies, conceivably because of low proportion of CL-related keratitis.

Although this study has a limitation that only a small numbers of patients at one tertiary referral center were included, we believe that this study provides updated data of infectious keratitis in a rural area of Korea, and can be informative particularly regarding infectious keratitis in rural areas. Further studies including larger population are needed for more generalized data.

\section{Acknowledgment}

Seung-Jun Lee and Jang Hun Lee share first authorship for this paper.

\section{Disclosure}

The authors report no conflicts of interest in this work.

\section{References}

1. Han SB, Lim TH, Wee WR, Lee JH, Kim MK. Current characteristics of infectious keratitis at a tertiary referral center in South Korea. Jpn J Ophthalmol. 2009;53(5):549-551.
2. McLeod SD, LaBree LD, Tayyanipour R, Flowers CW, Lee PP, McDonnell PJ. The importance of initial management in the treatment of severe infectious corneal ulcers. Ophthalmology. 1995;102(12): 1943-1948.

3. Prokosch V, Gatzioufas Z, Thanos S, Stupp T. Microbiological findings and predisposing risk factors in corneal ulcers. Graefes Arch Clin Exp Ophthalmol. 2012;250(3):369-374.

4. Hall RC, McKellar MJ. Bacterial keratitis in Christchurch, New Zealand, 1997-2001. Clin Experiment Ophthalmol. 2004;32(5):478-481.

5. Green M, Apel A, Stapleton F. Risk factors and causative organisms in microbial keratitis. Cornea. 2008;27(1):22-27.

6. van der Meulen IJ, van Rooij J, Nieuwendaal CP, Van Cleijnenbreugel H, Geerards AJ, Remeijer L. Age-related risk factors, culture outcomes, and prognosis in patients admitted with infectious keratitis to two Dutch tertiary referral centers. Cornea. 2008;27(5):539-544.

7. Bourcier T, Thomas F, Borderie V, Chaumeil C, Laroche L. Bacterial keratitis: predisposing factors, clinical and microbiological review of 300 cases. Br J Ophthalmol. 2003;87(7):834-838.

8. Chirinos-Saldana P, Bautista de Lucio VM, Hernandez-Camarena JC, et al. Clinical and microbiological profile of infectious keratitis in children. BMC Ophthalmol. 2013;13:54.

9. Feilmeier MR, Sivaraman KR, Oliva M, Tabin GC, Gurung R. Etiologic diagnosis of corneal ulceration at a tertiary eye center in Kathmandu, Nepal. Cornea. 2010;29(12):1380-1385.

10. Green M, Apel A, Stapleton F. A longitudinal study of trends in keratitis in Australia. Cornea. 2008;27(1):33-39.

11. Gupta N, Vashist P, Tandon R, Gupta SK, Dwivedi S, Mani K. Prevalence of corneal diseases in the rural Indian population: the Corneal Opacity Rural Epidemiological (CORE) study. Br J Ophthalmol. 2015;2:147-152.

12. Henry CR, Flynn HW Jr, Miller D, Forster RK, Alfonso EC. Infectious keratitis progressing to endophthalmitis: a 15 -year study of microbiology, associated factors, and clinical outcomes. Ophthalmology. 2012;119(12):2443-2449

13. Hahn YH, Hahn TW, Tchah HW, et al. Epidemiology of infectious keratitis(II): a multi-center study. J Korean Ophthalmol Soc. 2001;42(2):247-265.

14. Tchah HW, Kim JC, Hahn TW, Hahn YH. Epidemiology of contact lens related infectious keratitis (1995.4 1997.9): multi-center Study. J Korean Ophthalmol Soc. 1998;39(7):1417-1426.

15. Cohen EJ, Fulton JC, Hoffman CJ, et al. Trends in contact lensassociated corneal ulcers. Cornea. 1996;15(6):566-570.

16. Kunimoto DY, Sharma S, Garg P, Gopinathan U, Miller D, Rao GN. Corneal ulceration in the elderly in Hyderabad, south India. $\mathrm{Br} J$ Ophthalmol. 2000;84(1):54-59.

17. Keay L, Edwards K, Naduvilath T, et al. Microbial keratitis predisposing factors and morbidity. Ophthalmology. 2006;113(1):109-116.

18. Parmar P, Salman A, Kalavathy CM, Kaliamurthy J, Thomas PA, Jesudasan CA. Microbial keratitis at extremes of age. Cornea. 2006; 25(2):153-158.

19. Vajpayee RB, Dada T, Saxena R, et al. Study of the first contact management profile of cases of infectious keratitis: a hospital-based study. Cornea. 2000;19(1):52-56.

20. Yeh DL, Stinnett SS, Afshari NA. Analysis of bacterial cultures in infectious keratitis, 1997 to 2004. Am J Ophthalmol. 2006;142(6): 1066-1068.

21. Marangon FB, Miller D, Alfonso EC. Impact of prior therapy on the recovery and frequency of corneal pathogens. Cornea. 2004;23(2): $158-164$.

22. Sharma N, Goel M, Bansal S, et al. Evaluation of moxifloxacin $0.5 \%$ in treatment of nonperforated bacterial corneal ulcers: a randomized controlled trial. Ophthalmology. 2013;120(6):1173-1178.

23. Tuft SJ, Matheson M. In vitro antibiotic resistance in bacterial keratitis in London. Br J Ophthalmol. 2000;84(7):687-691.

24. Tan DT, Lee CP, Lim AS. Corneal ulcers in two institutions in Singapore: analysis of causative factors, organisms and antibiotic resistance. Ann Acad Med Singapore. 1995;24(6):823-829. 
International Medical Case Reports Journal

Dovepress

\section{Publish your work in this journal}

The International Medical Case Reports Journal is an international, peer-reviewed open-access journal publishing original case reports from all medical specialties. Previously unpublished medical posters are also accepted relating to any area of clinical or preclinical science. Submissions should not normally exceed 2,000 words or

4 published pages including figures, diagrams and references. The manuscript management system is completely online and includes a very quick and fair peer-review system, which is all easy to use. Visit $\mathrm{http}: / / \mathrm{www}$.dovepress.com/testimonials.php to read real quotes from published authors.

Submit your manuscript here: http://www.dovepress.com/international-medical-case-reports-journal-journal 